\title{
Analisis Sistem Apraisal pada Artikel Portal Berita Online Liputan 6 yang Berjudul Claudia Si Cantik Pemimpin Kartel Narkoba Mirip Kim Kardashian
}

\author{
Muhammad Aprianto Budhie Nugroho \\ Universitas Kuningan \\ email: muh.apriantobn@gmail.com
}

\begin{tabular}{l}
\hline \hline Article Info \\
\hline Article history: \\
Submitted Dec 31, 2019 \\
Revised Jan 17, 2020 \\
Accepted Feb 27, 2020 \\
Published April 30, 2020 \\
\hline
\end{tabular}

Keywords:

Appraisal system,

Affect,

Judgement,

graduation

\begin{abstract}
This reserach focus on apprasisal system analysis on an article entitled"Claudia si cantik pemimpin kartel narkoba mirip Kim Kadarshian". In this reserach the researcher uses descriptive qualitative method, the data is taken form the news portal liputan6.com that's afiliated in Surya Citra Televisi (SCTV). That text is analyzed by using appraisal system that focuse on attitude (affect, judgement, and appreciation) amplifying attitude and source of attitude (graduation). The result of this reserach shows that there are many positive apresiataion on Claudia eventhough Claudia is a drug lord.

Penelitian ini fokus pada analisis Apraisal pada sebuah artikel koran yang berjudul "Claudia si cantik pemimpin kartel narkoba mirip Kim Kadarshian". Didalam penelitian ini peneliti menggunakan metode penelitian deskriptif kualitatif, data dari penelitian ini adalah data yang diambil dari website liputan6.com, yang merubakan sebuah portal berita yang berafiliasai dengan Surya Citra Televisi (SCTV). Teks tersebut di analisis dengan sistem appraisal yang berfokus pada penilaian dari atittude (affect, judgement and appreciation) penguatan attitude dan sumber dari atitude (graduation). Hasil dalam penelitian memperlihatkan bahwa Appresiasi yang positif yang terdapat dalam teks tersebut, didalam teks tersebut banyak terdapat hal positif terutama pada penampilan dari Claudia walaupun Claudia adalah gembong Narkoba.
\end{abstract}

\section{Corresponding Author:}

Muhammad Aprianto Budie Nugroho

Universitas Kuningan,

Jalan Cut Nyak Dhien No. 36 A, Cijoho,

Kec. Kuningan, Kabupaten Kuningan, Jawa Barat 45513

Email: muh.apriantobn@gmail.com

\section{PENDAHULUAN}

Pada era globasisasi saat ini dan didukung dengan akses internet yang kuat dan terjangkau kita bisa mendapatkan berita dengan cepat baik melaului media elektronik yang berupa media berita online. Masyarakat pada saat ini yang 
cenderung bergerak cepat dan membutuhkan sesuatu yang instan lebih mememilih membaca melalui media berita online karena media berita online mampu menyuguhkan berita dengan cepat dan bisa diakses dimana saja dan kapan saja. Salah satu media berita online adalah liputan6.com, situs berita online ini adalah situs berita yang berangkat dari sebuah acar berita yaitu liputan 6 yang disiarkan oleh Surya Citra Televisi (SCTV).

Didalam penelitian ini peneliti menggunakan sistem Appraisal dalam menganalisis sebuah artikel koran yang di kutip dari sebuah situs berita online yaitu liputan6.com yang berjudul "Claudia si cantik pemimpin kartel narkoba mirip Kim Kardashian ". Didalam artikel tersebut bercerita mengenai seorang gembong narkoba dari negara Mexico yang berbeda dari yang lain. Nama gembong tersebut adalah Claudia Ochoa Felix, dia adalah seorang gembong narkoba yang berjenis kelamin perempuan yang biasanya para gembong narkoba biasanya berjenis kelamin pria yang biasanya bertampang garang dan menyeramkan. Berbeda dengan Claudia, dia adalah seorang gembong narkoba yang cantik dan seksi bahkan dia disamakan dengan salah satu selebriti yaitu Kim Kadarshian, Kim Kadarshian adalah selebriti reality show yang dianggap seksi.

Peneliti menggunakan piranti appraisal yang dikemukakan oleh White (1998) di dalam menganalisa artikel koran tersebut, karena menurut Martin \& Rose, sistem appraisal mengacu pada penilaian yang berkaitan dengan evaluasi, sikap-sikap yang dinegosiasikan di dalam sebuah teks, kekuatan emosi dan perasaan yang terlibat dan dapat diamati di dalam sebuah teks, serta bagaimana nilai-nilai mengenai sesuatu hal [atau benda dihasilkan dan disesuaikan dengan pembaca (2003:6). Sistem appraisal berhubungan dengan salah satu metafungsi bahasa, yaitu sistem interpersonal. Oleh karena itu appraisal berkaitan erat dengan pelibat komunikasi dan hubungan sosial diantara para pelibat komunikasi tersebut. Hope \& Read (dalam Wiedarti, 2006: 1) membagi appraisal system (penilaian) menjadi tiga kategori, yaitu attitude yang terdiri dari affect, judgement, appreciation selain itu, terdapat graduation, dan engagement.

\section{TEORI DAN METODOLOGI}

Sistem appraisal merupakan pengembangan teori LSF pada ranah makna interpersonal. Martin \& Rose (2003: 22) mendefinisikan appraisal sebagaisebuah sistem makna interpersonal yang mengacu pada evaluasi attitude yang terdapat dalam teks, bagaimana seseorang mengekspresikan seberapa kuat perasaannya terhadap suatu hal dan bagaimana nilai-nilai terhadap suatu hal di dalam teks tersebut dihasilkan. Dengan kata lain, dengan menggunakan teori appraisal kita bisa memberitahu pembaca atau orang lain mengenai attitude dan perasaan kita mengenai suatu hal atau seseorang. Martin \& White (2005: 33) menuliskan bahwa appraisal merupakan salah satu dari tiga sumber utama semantik wacana yang menguraikan makna interpersonal di samping involvement dan negotiation. Appraisal dibagi menjadi tiga domain yaitu attitude, engagement, dan graduation

Unsur emosi ini disebut dengan affect, yang secara mudah dapat diterjemahkan menjadi aspek "afektif", yang berkutat pada sikap suka atau tidak suka dengan semua varian dan gradasinya. Mereka menyebutkan bahwa etika atau judgment dan apresiasi itu hanyalah bentuk perasaan atau emosi yang terlembaga 
sebagai kehendak (proposal), sementara apresiasi adalah emosi yang terlembaga dalam bentuk pernyataan (proposisi).

Penilaian (judgement) berkaitan dengan sikap kita terhadap perilaku; kita bisa menghargai, mengkritik, memuji atau sebaliknya mengutuk (Martin and White, 2005:42). Judgement mengoperasionalkan ulang dalam ranah tata aturan dari perilaku-apa yang seharusnya dilakukan atau tidak; sebagian dari tata aturan ini kemudian terformatkan dalam bentuk aturan dan undang-undang yang diberlakukan oleh lembaga agama dan negara (Martin and White, 2005:42). Sebagian lainnya hanya menjadi norma, konvensi dan kepantasan etika yang dibagi bersama oleh anggota budaya tertentu, baik dalam lingkup yang paling sempit hingga yang paling luas.

Sementara itu, apresiasi (appreciation) melibatkan evaluasi fenomena semiotik atau pun alamiah, berdasarkan kaidah penilaian yang sesuai dengan bidangnya. Berbeda dengan judgement, apresiasi mewujudkan ulang perasaan dalam bentuk proposisi-proposisi tentang nilai "sesuatu"—apakah sesuatu itu bermanfaat atau sebaliknya; sebagian apresiasi ini di masyarakat terlembaga dalam sistem penghargaan (harga, tingkat, hibah, hadiah, dan penghargaanpenghargaan serupa) (Martin and White, 2005:42). Apresiasi lebih merujuk pada nilai-nilai kebendaan di luar manusia itu sendiri, berbeda dengan judgment yang obyeknya adalah perilaku manusia. Meskipun, hal atau sesuatu itu juga terkait dengan manusia baik langsung atau pun tidak langsung.

Di dalam penelitian ini peneliti menggunakan metote penelitian kualitatif deskriptif dalam menganalisis artikel koran yang berjudul "Claudia si cantik pemimpin kartel narkoba mirip Kim Kardashian". Lincoln \& Guba dalam Santosa (2014: 28) mengatakan bahwa ciri penelitian kualitatif adalah adanya penggunaan pengetahuan intuitif di samping pengetahuan proposisi atau diskursif yang diekspresikan dalam bahasa. Penelitian ini juga bersifat deskriptif karena bertujuan untuk mendeskripsikan secara rinci fenomena-fenomena yang dikaji di lapangan (Sutopo, 2006).

Metode penelitian bahasa berkaitan dengan tujuan penelitian serta melibatkan pengumpulan dan pemilihan data. Penelitian ini mendeskripsikan hasil temuan dari analisis appraisal pada pemberitaan tentang seorang gembong wanita narkoba dari Meksiko yang bernama Claudia, Claudia ini berbeda dengan typikal seorang gembong narkoba yang biasanya garang dan menakutkan, Claudia bahkan dianggap mirip dengan seorang selibritis yang terkenal bernama Kim Kadarshian. berita tersbut dikutip dari media berita online liputan6.com pada website https://www.liputan6.com/global/read/2059906/claudia-si-cantik-pemimpinkartel-narkoba-mirip-kim-kardashian

\section{HASIL DAN PEMBAHASAN}

Berikut ini akan dijabarkan hasil dari analisis Apraisal pada artikel berita yang bejudul "Claudia si cantik pemimpin kartel narkoba mirip Kim Kardashian" yang diambil dari situs berita online liputan6.com.

1. Sistem Appraisal pada teks artikel mengenai Claudia di media online liputan6.com

Tabel berikut ini menjelaskan jumlah dari teks mengenai Claudia Ochoa Felix piranti Apprasial yang teridentifikasi 
Tabel 1 Piranti Appraisal yang teridentifikasi pada Teks artikel mengenai Claudia Ochoa Felix

\begin{tabular}{ll}
\hline \multicolumn{1}{c}{ Piranti Appraisal } & Temuan Data \\
\hline \hline 1. Attitude & \\
a. Affect & 1 \\
i. Affect positif langsung & - \\
ii. Affect positif tersirat & - \\
iii. Affect negatif langsung & - \\
iv. Affect negatif tersirat & 2 \\
b. Judgement & - \\
i. Moral Judgement Positif langsung & \\
ii. Moral Judgement Positif tersirat & - \\
iii. Moral Judgement negatif langsung & 9 \\
iv. Moral Judgement negatif tersirat & - \\
v. Personal Judgement Positif langsung & - \\
vi. Personal Judgement Positif tersirat & - \\
vii. Personal Judgement negatif langsung & 3 \\
viii. Personal Judgement negatif tersirat & 2 \\
c. Apreciation & \\
i. Appreciation positif & \\
ii. Appreciation negatif & 2 \\
2. Amplification & - \\
a. Force & - \\
i. Intensifier & - \\
ii. Attitudinal Lexis & \\
iiii. Metaphor & \\
iv. Swearing & - \\
b. Focus & \\
i. Sharphen & \\
ii. Soften & \\
3. Source of appraisal & \\
a. Monogloss & \\
b. Heterogloss & \\
\hline
\end{tabular}

Sebagian piranti appraisal yang teridentifikasi di dalam teks berita mengenai Claudia Ochoa Felix dalam portal berita online liputan6.com adalah sebagai berikut:

Tabel. 2 Piranti Appraisal yang teridentifikasi di dalam teks mengenai Claudia Ochoa Felix dalam portal berita online liputan6.com

\begin{tabular}{|c|c|}
\hline Piranti Appraisal & Temuan Data \\
\hline \multicolumn{2}{|l|}{ 1. Attitude } \\
\hline \multicolumn{2}{|l|}{ 1.1. Affect } \\
\hline $\begin{array}{l}\text { 1.1.1. Affect } \\
\text { langsung }\end{array}$ positif & $\begin{array}{l}\text { Sosoknya justru cantik nan memikat hati } \\
\text { siapapun yang memandangnya. }\end{array}$ \\
\hline 1.1.2. Affect positif tersirat & \\
\hline $\begin{array}{cc}\text { 1.1.3. } \begin{array}{c}\text { Affect } \\
\text { langsung }\end{array} & \text { negatif } \\
\end{array}$ & \\
\hline 1.1.4. Affect negatif tersirat & \\
\hline \multicolumn{2}{|l|}{ 1.2. Judgement } \\
\hline $\begin{array}{l}\text { 1.2.1. Moral Judgement } \\
\text { Positif langsung }\end{array}$ & \begin{tabular}{|l} 
2.1.1. \\
$\begin{array}{l}\text { Claudia si Cantik Pemimpin Kartel Narkoba Kardashian. } \\
\text { M.1.2. }\end{array}$ \\
$\begin{array}{l}\text { Si cantik nan seksi Claudia juga dijuluki The } \\
\text { Empress of Antrax }\end{array}$
\end{tabular} \\
\hline
\end{tabular}




\begin{tabular}{|c|c|c|}
\hline $\begin{array}{l}\text { 1.2.2. Moral Judgement } \\
\text { Positif tersirat }\end{array}$ & & \multirow[b]{2}{*}{$\begin{array}{l}\text { dianggap pemimpin baru skuad 'Los Antrax', } \\
\text { kelompok beking yang digunakan oleh kartel } \\
\text { (penjual narkoba) Sinaloa untuk melakukan } \\
\text { eksekusi dan serangan balas dendam. } \\
\text { Mereka disebut-sebut sebagai dalang banyak } \\
\text { penyelundupan heroin ke Amerika Serikat. } \\
\text { adalah skuad elite pembunuh bayaran kartel } \\
\text { obat-obatan terlarang itu, yang sebelumnya } \\
\text { dipimpin oleh kekasihnya, Jose Rodrigo } \\
\text { Arechiga Gamboa. } \\
\text { Jika ada 'pekerjaan kotor' yang perlu } \\
\text { diselesaikan, Los Antrax yang akan } \\
\text { melakukannya. } \\
\text { Mereka juga bertanggung jawab atas keamanan } \\
\text { bos kartel narkoba Ismael 'El Mayo' Zambada. }\end{array}$} \\
\hline $\begin{array}{l}\text { 1.2.3. Moral Judgements } \\
\text { negatif langsung }\end{array}$ & $\begin{array}{l}.2 .3 .2 . \\
.2 .3 .3 .\end{array}$ & \\
\hline \multicolumn{3}{|l|}{$\begin{array}{l}\text { 1.2.4. Moral Judgements } \\
\text { negatif tersirat }\end{array}$} \\
\hline $\begin{array}{l}\text { 1.2.5. Personal Judgement } \\
\text { Positif langsung }\end{array}$ & $\begin{array}{r}.2 .5 .1 . \\
.2 .5 .2 . \\
.2 .5 .3 . \\
.2 .5 .4 . \\
.2 .5 .5 . \\
.2 .5 .6 . \\
.2 .5 .7 .\end{array}$ & $\begin{array}{l}\text { Claudia si Cantik Pemimpin Kartel Narkoba } \\
\text { Mirip Kim Kardashian. } \\
\text { Sosoknya justru cantik nan memikat hati } \\
\text { siapapun yang memandangnya. } \\
\text { pemimpin salah satu kelompok kartel } \\
\text { narkoba di Meksiko ini begitu cantik. } \\
\text { Wanita yang memiliki rupa mirip selebriti Kim } \\
\text { Kardashian ini bernama Claudia Ochoa Felix. } \\
\text { Si cantik nan seksi Claudia juga dijuluki The } \\
\text { Empress of Antrax } \\
\text { Wanita berusia } 27 \text { tahun itu kerap } \\
\text { menggunakan media sosial untuk pamer gaya } \\
\text { hidupnya yang glamor. } \\
\text { Ia memposting foto dirinya memegang senjata } \\
\text { dan berpose dalam balutan kostum seksi } \\
\text { bermotif macan tutul mirip dengan kepunyaan } \\
\text { Kim Kardashian } \\
\text { Pose seksinya dengan pakaian ketat dan } \\
\text { pakaian renang yang memperlihatkan } \\
\text { beberapa bagian tubuhnya pun tak luput ia } \\
\text { posting. } \\
\text { Meskipun bergaya hidup mewah Claudia } \\
\text { awalnya tak begitu dikenal publik }\end{array}$ \\
\hline \multicolumn{3}{|l|}{$\begin{array}{l}\text { 1.2.6. Personal Judgement } \\
\text { Positif tersirat }\end{array}$} \\
\hline \multicolumn{3}{|l|}{$\begin{array}{l}\text { 1.2.7. Personal Judgement } \\
\text { negatif langsung }\end{array}$} \\
\hline \multicolumn{3}{|l|}{$\begin{array}{c}\text { 1.2.8. Personal Judgement } \\
\text { negatif tersirat }\end{array}$} \\
\hline 1.3. Apreciation & & \\
\hline 1.3.1. Appreciation positif & $\begin{array}{c}.3 .1 .1 . \\
.3 .1 .2 . \\
.3 .1 .3\end{array}$ & $\begin{array}{l}\text { Claudia si Cantik Pemimpin Kartel Narkoba } \\
\text { Mirip Kim Kardashian. } \\
\text { Sosoknya justru cantik nan memikat hati } \\
\text { siapapun yang memandangnya. } \\
\underline{\text { Si cantik nan seksi Claudia juga dijuluki The }} \\
\text { Empress of Antrax }\end{array}$ \\
\hline
\end{tabular}




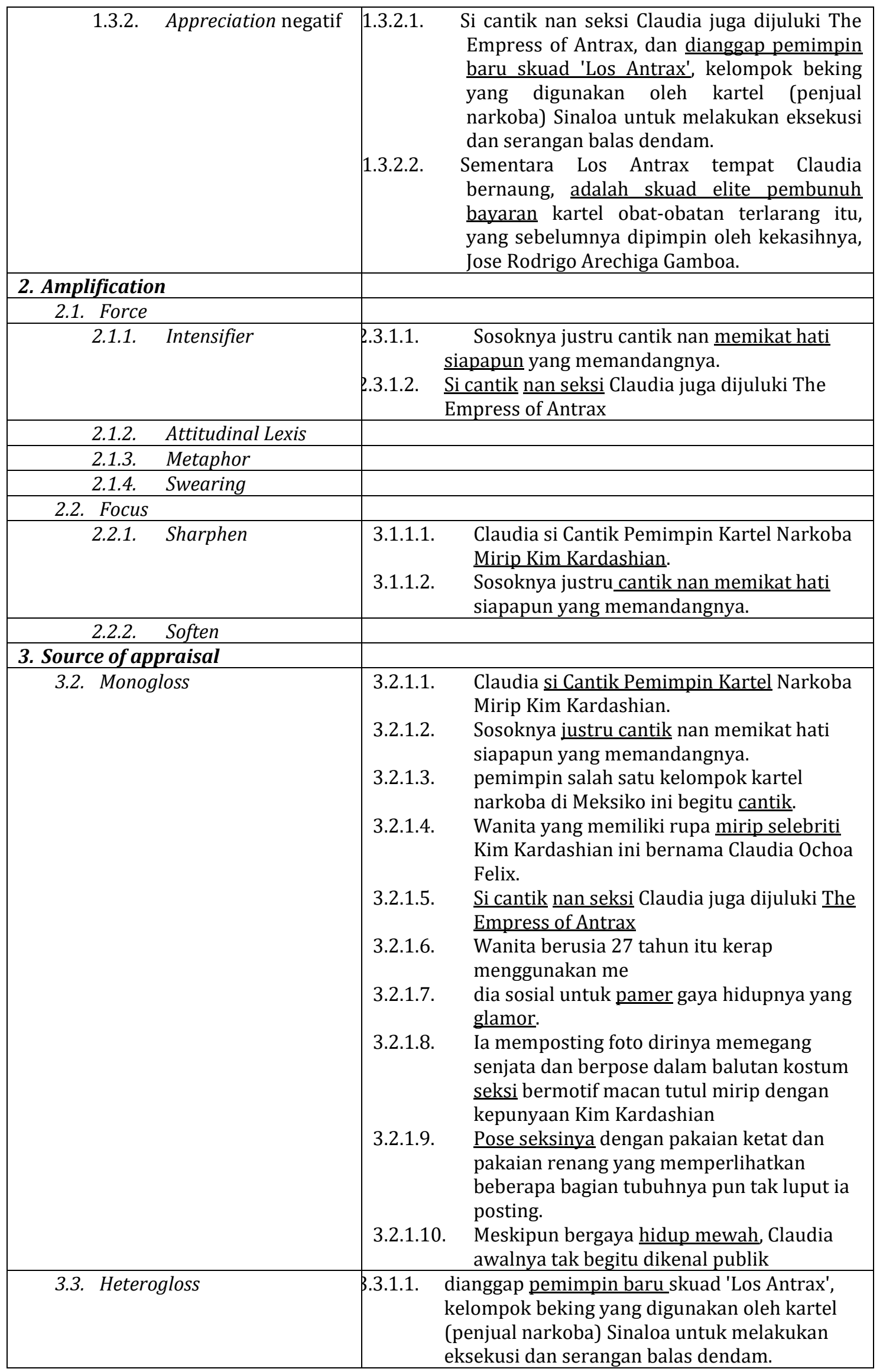




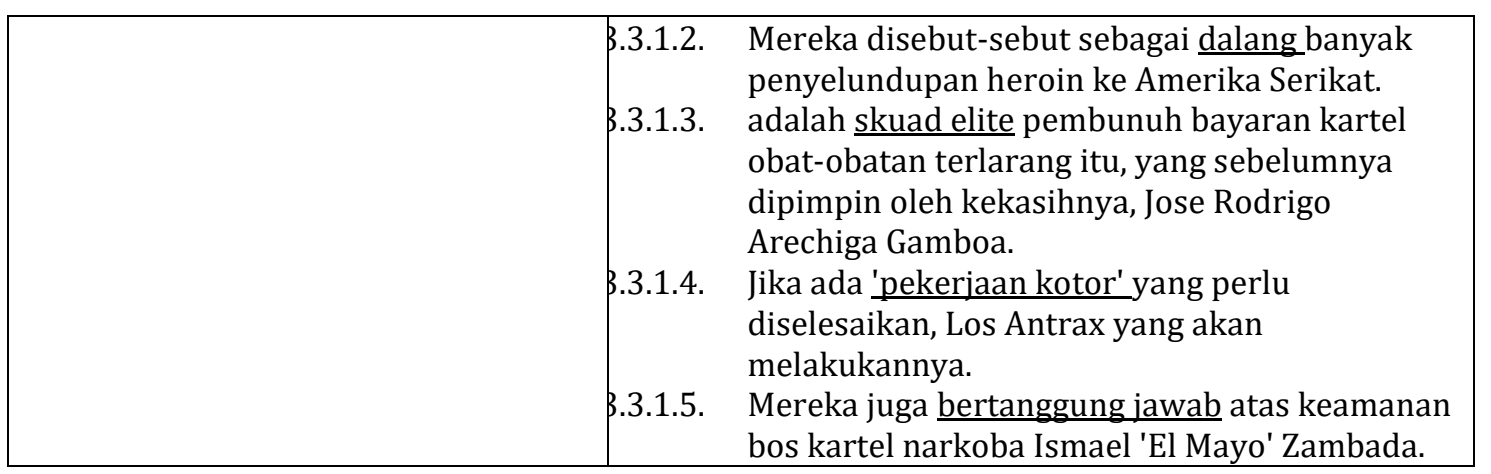

Teks artikel dalam portal harian online yang berjudul "Claudia si cantik pemimpin kartel narkoba mirip Kim Kardashian" , adalah sebuah artikel berita yang menceritakan seorang gembong narkoba yang bernama Claudia Ochoa Felix. Claudia diangkat dalam berita tersebut karena dia adalah salah satu gembong narkoba yang berjenis kelamin wanita dan mempunyai paras cantik dan bertubuh seksi. Affect positif dalam berita tersebut bisa dilihat dari perasaan positif di clausa Sosoknya justru cantik nan memikat hati siapapun yang memandangnya. Kata memikat hati yang bermakna bahwa kecantikan parasnya membuat orang jatuh hati padanya terlepas dia adalah seorang gembong narkoba yang berbahaya.

Judgement personal positif juga terlihat pada sosok Claudia, hal tersebut bisa dilihat pada salah satu clausa; Sosoknya justru cantik nan memikat hati siapapun yang memandangnya. Kata cantik sendiri adalah memperlihatkan penilaian dari sang penulis bahwa kecantikan dari Claudia membuatnya berbeda dari gembong narkoba yang biasanya lelaki yang berwajah garang dan kasar.

Penjelasan diatas juga memperlihatkan mengenai sumber dari atitude yang merupakan monoglos, sumber dari penilaian atau appraisal dari atitude tersebut sepenuhnya dari penulis berita, sedangkan beberapa lainnya yang merupakan heteroglos yang sumbernya bukan saja dari penulis tapi didaptkan dari lembaga penegak hukum, hal tersebut bisa dilihat dari clausa; dianggap pemimpin baru skuad 'Los Antrax', kelompok beking yang digunakan oleh kartel (penjual narkoba) Sinaloa untuk melakukan eksekusi dan serangan balas dendam. Penggunaan phrasa pemimpin baru memperlihatkan bahwa sumber informasi posisi yang didapatkan oleh penulis melalui lembaga penegak hukum.

\section{SIMPULAN}

Dari analisis teks yang berjudul "Claudia si cantik pemimpin kartel narkoba mirip Kim Kadarshian" bisa ditarik sebuah kesimpulan bahwa aspek yang ditonjolkan dalam teks tersebut adalah penampilan fisik dari seorang gembong narkoba bernama Claudia Ochoa Felix. Teks tersebut lebih menonjolkan kualitas fisik dari Claudia dan posisinya yang dianggap tinggi, setara dengan gembong narkoba lainnya yang berjenis kelamin pria, padahal Claudia adalah seorang pemimpin dari kelompok pembunuh elit.

\section{REFERENSI}

Martin, J.R and Rose, David. 2003. Working with discourse: meaning beyond the clause. London: Continuum 
Martin, J.R. \& White, P.R.R. 2005. The language of evaluation: appraisal in English. New York: Palgrave Macmillan.

Santosa, R. 2014. Metode penelitian kualitatif kebahasaan. Universitas Sebelas Maret Surakarta.

Sutopo, H.B. 2006. Metodolgi penelitian kualitatif: dasar teori dan terapannya dalam penelitian. Surakarta: UNS Press

Yulianti, Tanti. 2014. Claudia si cantik pemimpin kartel narkoba mirip Kim Kadarshian. https://www.liputan6.com/global/read/2059906/claudia-sicantik-pemimpin-kartel-narkoba-mirip-kim-kardashian

White, P.R.R. 1998. Telling media tales: the news story as rhetoric. Unpublished Research. Phd Theses. Sydney: University of Sydney 